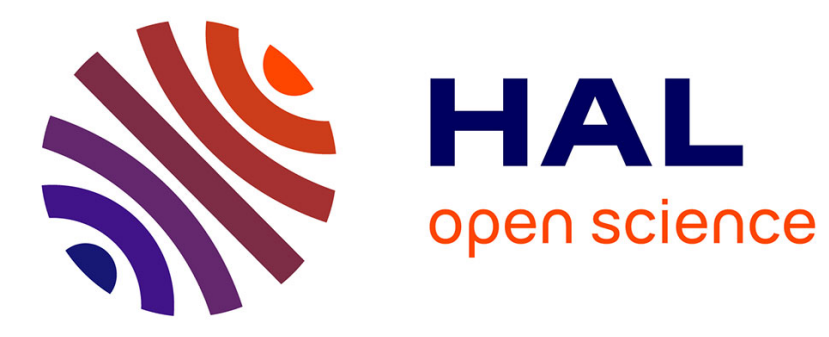

\title{
What Students Learn with Personal Data Physicalization
}

\author{
Charles Perin
}

\section{To cite this version:}

Charles Perin. What Students Learn with Personal Data Physicalization. IEEE Computer Graphics and Applications, inPress, 10.1109/MCG.2021.3115417 . hal-03360714

\section{HAL Id: hal-03360714 \\ https://hal.inria.fr/hal-03360714}

Submitted on 1 Oct 2021

HAL is a multi-disciplinary open access archive for the deposit and dissemination of scientific research documents, whether they are published or not. The documents may come from teaching and research institutions in France or abroad, or from public or private research centers.
L'archive ouverte pluridisciplinaire HAL, est destinée au dépôt et à la diffusion de documents scientifiques de niveau recherche, publiés ou non, émanant des établissements d'enseignement et de recherche français ou étrangers, des laboratoires publics ou privés. 


\title{
What Students Learn with Personal Data Physicalization
}

\author{
Charles Perin \\ University of Victoria
}

\begin{abstract}
I describe the results of implementing a personal data physicalization assignment in an information visualization course for senior undergraduate and graduate students in computer science and software engineering. By collecting data about themselves and representing this data in physical forms, students were able to i) learn about data visualization, ii) design creatively; and iii) learn about themselves. While data physicalization in education has been explored with non-technical and novice audiences, the experience I report in this paper provides evidence that data physicalization also has benefits for technical, visualization-savvy students.
\end{abstract}

Index Terms: Visualization, Physicalization, Personal Data, Education.

INSTRUCTORS of visualization courses often complain (through informal discussions) that technical students struggle think beyond the prescribed set of a dozen or so of standard charts, widely available on the web, in visualization software and in charting libraries. From experience, students are often convinced they are not creative, and are even reticent to grab pen and paper for the first few sketching sessions in a course. Students capable of technical wonders often complete assignments and projects that replicate yet another pie chart linked to a stacked barchart.

In this paper, I discuss the personal data physicalization assignment part of the information Visualization course for Computer Science (CS) and Software Engineering (SE) students at the University of Victoria. Two thirds of the 60-70 students are fourth year undergraduates, the remaining third being graduate students. This assignment builds on two visualization research trends: personal visualization and physicalization.

Personal visualization [1] (or "casual" visual- ization [2]) is concerned with empowering people with data visualizations. The aim is to support people in collecting and analyzing personal data to generate insights and make informed decisions in their everyday lives. When visualizing personal data, people tend to not use basic chart layouts that resemble default Excel and Tableau templates, but instead to think more creatively as they seek subjectivity [3], emotional connection [4], remembrance [5], storytelling [6], and self-reflection [7], [8]. While personal visualization has the potential to increase student motivation and creativity, this potential is weakened if students go back to using the same standard libraries and tools they are familiar with. This is where physicalization comes into play.

Research on data physicalization [9] is relatively recent, and we have little resources about how it is taught as part of a visualization course or curriculum. What we know is that constructing physical visualizations can facilitate learning, especially for people with limited visualization knowledge [10], [11]. Several workshops have been successfully run, typically in small groups, in-person, in a collaborative workshop format [12], [13]. Although such activities have been adapted to classroom environment with ped-

This is the author version of the work - 2021. 
agogical goals [14], they are typically designed to engage a non-technical audience, using constrained low-tech materials and targeted at novice visualization learners [15]. Physicalization has been taught in a dedicated course [16], and in a design studio [17], but the environments are different from ours. The taxonomy for data sculpture by Moere and Patel [17] is based on observations conducted in small class sizes (around 28 students), in a Design Computing course and in a studio-based, guided environment. In addition, although students were asked to "establish a remarkable or worthwhile insight that underlies a specific, potential data pattern they were personally interested in", the data used was not personal and there was no data collection phase.

To the best of my knowledge, there is no empirical reflection on using personal data physicalization in teaching visualization. In the following, I describe such an assignment I designed as part of an information visualization course. Next, I summarize my analysis of student assignments and discuss how students learned about various aspects of visualization (data collection, physical and visual mappings, interaction design), as well as how they learned about themselves.

\section{ASSIGNMENT DESCRIPTION}

Two versions of the assignment were used. Below I summarize these two versions and the rationale for changes based on student feedback.

Students were asked to create physical representations of data they had collected, to describe their data, the reasons why they chose this data, to formulate data questions, why they were interested in these questions and why visualization is a good approach to answering these questions. They designed physicalizations and were asked to describe and provide rationale for their choice of materials, visual marks and visual variables. They were also asked to explain how the visualization helps answer some of their data questions. Students are not allowed to submit a computerassisted design nor a sketch. They must rely on physical objects around them and they can "use any other material and process [they] can think of, such as plasticine, paper folding, play-doh, clay, wood, sand, water, cardboard, lego blocks, matches, beer, food, tree leaves, grass, rocks".

In its first version, the assignment had six deliverables, one to two weeks apart ${ }^{1}$.

1) Data collection and questions 1: students collected one week of personal data of their choice and formulated three data questions (questions they would like to find answer to related to this data), with an emphasis on time. 2) Visualization Design 1: they designed a visualization with a temporal component to it, that (partly) addresses their data questions. 3) Data collection and questions 2: they collected one more week of the same data, and formulated three new data questions, this time with an emphasis on comparison. 4) Visualization Design 2: they designed a visualization that addresses comparison questions about their two weeks of data. 5) Visualization Design 3: they designed a visualization that combines as much as possible their two previous designs, and that addresses as many of their six data questions as possible. 6) Video Report: they produced a 3-minute video that describes their data and their different designs, as well as some personal data insights and a reflection on the process.

This assignment was designed so that students achieve the following course-level intended learning outcomes (ILO).

- ILO1 - You will develop an understanding of data collection and the importance of data collection in data visualization and analysis - is achieved through the data collection and reflection stages.

- ILO2 - Given a dataset, you will formulate data questions that visualization can help address and ILO 3 - Given a dataset and a data question, you will create several design variations applying principles of good visualization design - are achieved through the data collection, formulation of data questions, and ideation stages.

- ILO4 - Given a simple dataset, you will create several design variations using different visual marks and visual variables - is achieved through exploring different designs and different materials in the ideation stages.

Overall, students did great in this assignment and enjoyed the process. However, their feedback

\footnotetext{
${ }^{1}$ http://web.uvic.ca/ $\sim$ cperin/teaching/2019/infovis/ personal-data-project/personal-data-project.html
} 
also outlined that: i) there were too many redundant parts to the assignment; and ii) students found it difficult, and a waste of time, to combine two visualizations into a third one.

The second iteration is therefore a simpler version $^{2}$. It includes only one data collection phase (two weeks of data), one design ideation phase, and one deliverable (the 3-minute long video report). Their design must encode the temporal dimension and allow for comparison.

I found that this second version allowed students to accomplish similar learning outcomes than with the first one, while being much less demanding. In the following, I discuss what students learned and the benefits of such assignments.

\section{METHODOLOGY}

I created this assignment as part of a Course Design/Redesign grant from the Division of Learning and Teaching Support and Innovation at the University of Victoria. To evaluate this redesign, ethics approval was obtained from the Human Research Ethics Board at the University of Victoria (\#18-1239). This allowed me to analyze material created by students in the course, including assignments (students were given the opportunity to opt out from the study at any time).

Data collected and analyzed for this research consists of i) written assignment deliverables (text and images); ii) final video assignment report; and iii) a written report in which students reflect on their learning for the entire course. Although three cohorts of students participated in the assignment, only the first two participated in the study. The ethics protocol was not adapted to remote teaching during the pandemic, therefore for the third cohort, the data was not analyzed but students were asked at the end of the course if they granted permission to the instructor to utilize images of their physicalizations for publication. In the following, images are credited by name or anonymized based on student preference. Quotes are either direct extracts from written assignments or transcribed from the video report.

\section{DATA COLLECTION}

This assignment starts with data collection. Students must decide what data to collect, jug-

\footnotetext{
${ }^{2}$ http://web.uvic.ca/ cperin/teaching/2021/infovis/documents/ personal-vis.html
}

gling between too simple and too ambitious datasets. Some would collect large amounts of data, for example P53 collected hourly recordings of location, who they are with, the weather, their mood, food and water consumption, primary activity, and next assignment due date. Over one third of the students commented on how painful (ambitious) data collection was. For example, they said it was "Very time consuming" (P15, P16, P29), that "This process [of collecting data] was a huge pain" (P51), and that "Tracking the data consistently is hard" (P14).

This part of the assignment forces students to think about data collection. For example, P107 said "One of the challenges was to decide which activity to record when collecting the data." Students made subjective choices in terms of what data to track or not, and at which accuracy, a phenomenon often observed when collecting data for personal visualization [3]. Some also invented strategies that made them more effective at collecting data. For example, P119 said: "During the second week of data collection, I switched to just taking a photo inside my pocket to record transit information since I can do this quickly using the phone's button shortcuts, and the metadata of the photo records the time, date and location." P16 decided after a few days to create a custom Google Form to more quickly enter their data about their activity levels and automatically storing it in a spreadsheet with a timestamp.

Interestingly, over two thirds of the students used a combination of automatic and manual data collection methods. Many used apps and websites such as MyFitnessPal, ScreenTime, Last.fm, Fitbit app and Google Timeline to retrieve personal data; but this data was not enough. These automatic data collection methods were complemented with manual logging, often on their phones, using apps such as Toggl or simple notepad applications; a handful even logged everything with pen and paper, outlining the limitations of these automatic data collection tools. Many of the students collected manually data that was very personal, often intimate even. Nearly half of the students collected data related to their mood, stress, or mental and physical health, data that is subjective and hard to collect automatically. Most popular topics include mental health, mood, stress, sleep, calories intake, food 

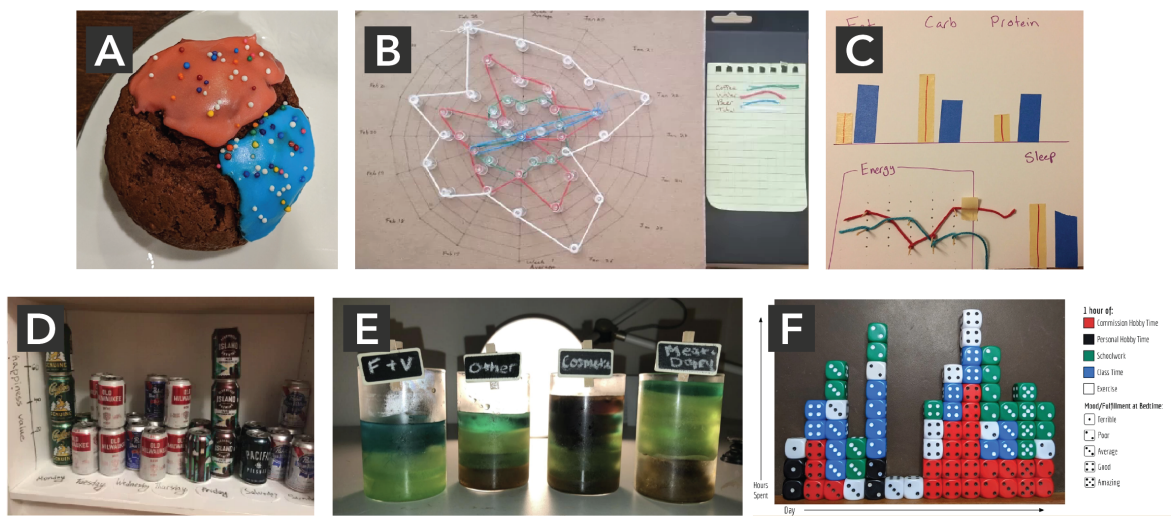

Figure 1. Examples of reproductions of standard charts using physical material. (A) A pie chart on a muffin shows music listening habits (P51, Hunter Watson). (B) A spider chart made of pins and threads shows different fluid intakes (P55, James Ryan). (C) Barcharts and line charts show sleep, energy levels and eating habits (P27, Colin Malloy). (D) A bar chart made of beer cans shows happiness per day and according to the music being listened to (P4, Aigerim Mashkanova). (E) A stacked barchart made of liquids of different colors and viscosity shows environmental impact as measured through products used (P29, Courtney Maricle). (F) A stacked barchart made of dice shows mood for each activity recorded each day (P69, Andrew LaRiviere).
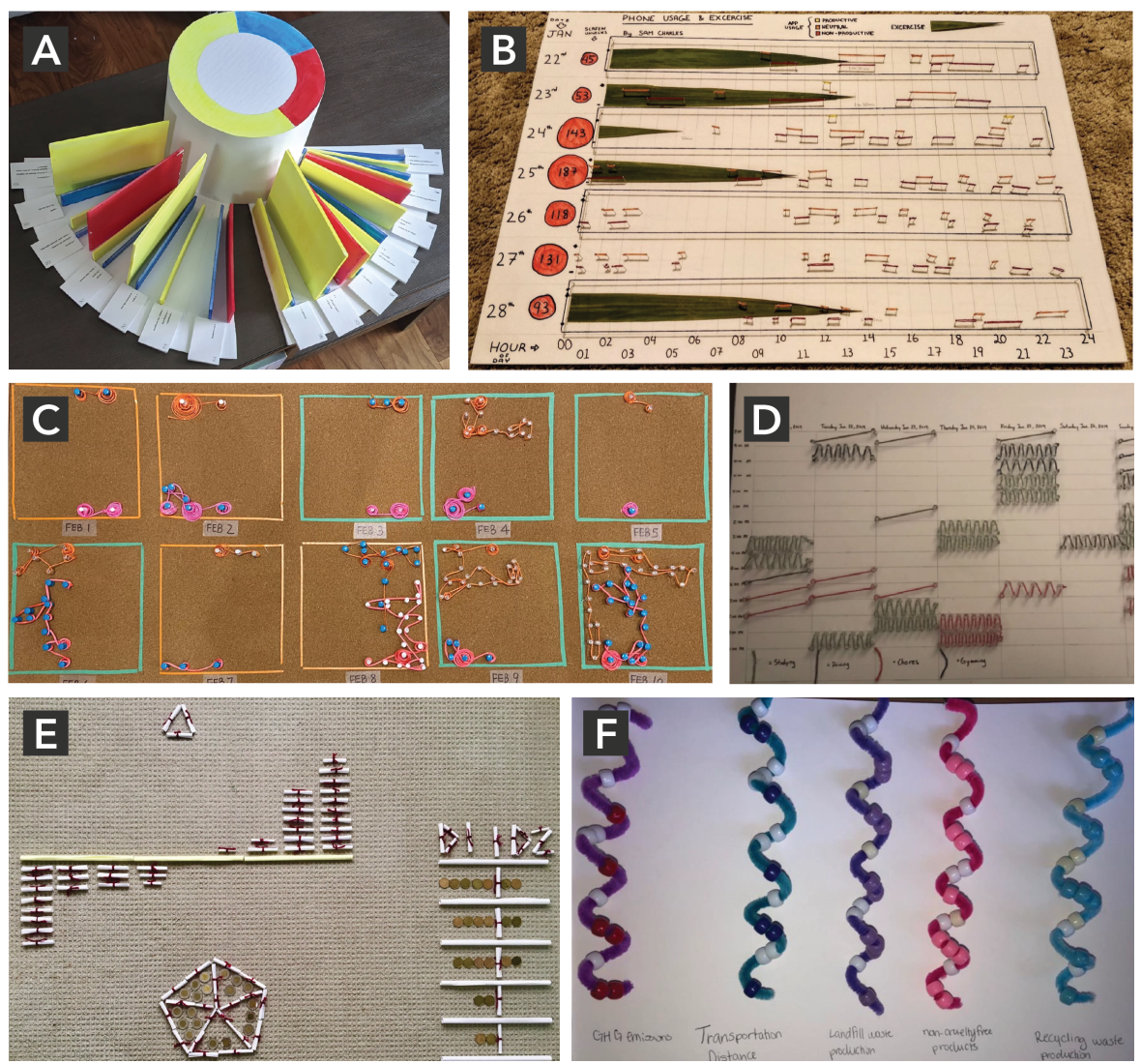

Figure 2. Examples of bespoke layouts. (A) A $3 d$ structure shows language learning history (P90, Vincent Potrykus). (B) Bubbles, bars, and intervals show phone app usage (P94, Sam Charles). (C) Pins show the positions of the kings in 10 chess games; threads connect successive positions and loops around a pin show how long a king stayed at that position (P24). (D) Patterns with different frequencies in a calendar grid show music listening habits (P8, Andrew Yang). (E) Small paper rolls are used to represent news articles read as well as to create structure (P31). (F) Pipe cleaners and beads show environmental impact (P29, Courtney Maricle). 

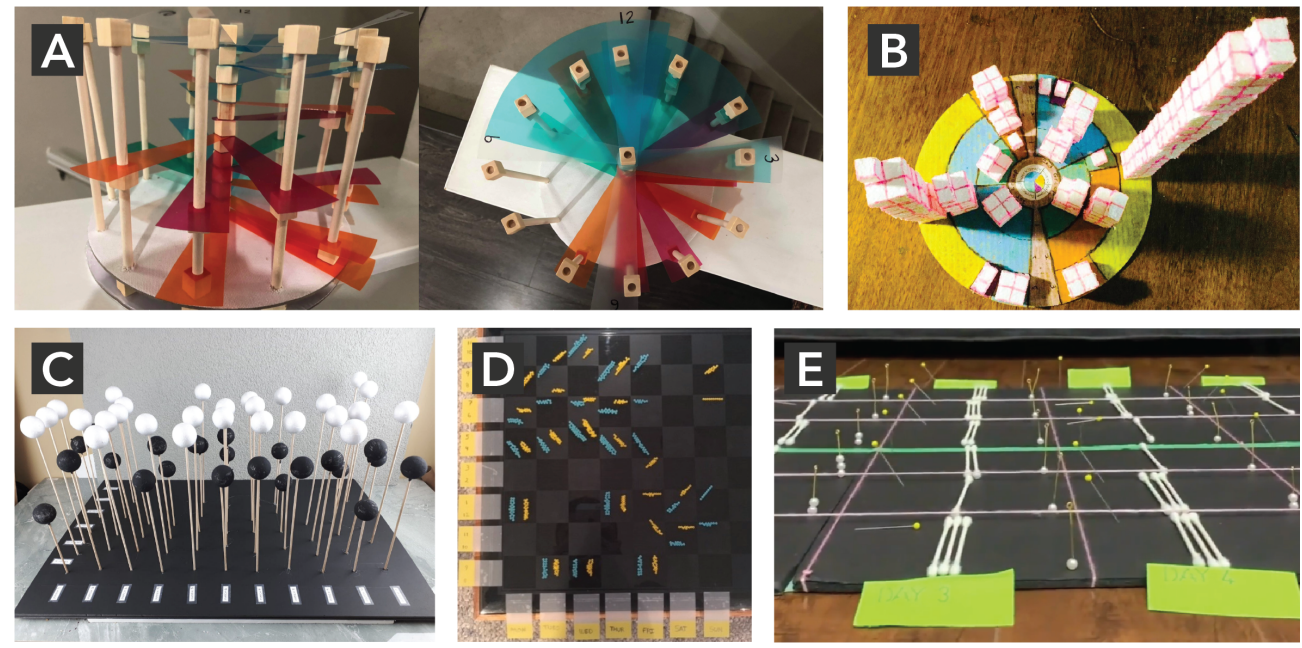

Figure 3. Examples of physicalizations making use of $3 d$, volume and orientation. $3 d$ structures show (A) the time at which music was played (P19), (B) email communications (P20, Charlie Zhang), and (C) results in played squash games (P25, Chris Cook). Orientation is used to represent (D) travel patterns (P40, Dylan Legebokow) and (E) productivity (P96).

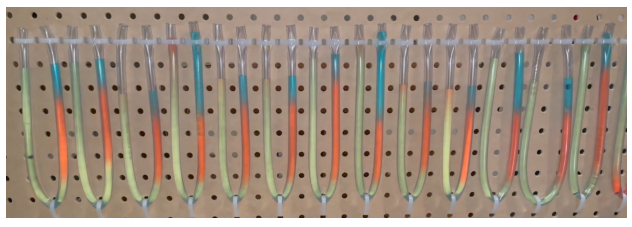

Figure 4. Showing mood, sleep and exercise using liquid in tubes; gravity allows to see which color is at the midpoint of the tube (P12).

and drink consumption, music listening history, screen time, gaming, and sports activities. All students ended up collecting at least two different types of data, hoping to identify correlations. Around $95 \%$ of the student used a spreadsheet software like Excel or Google Spreadsheets to store, organize and utilize the data.

\section{PHYSICAL AND VISUAL MAPPINGS}

Students had to choose and explain their data mappings using physical and visual variables. Around half the students reproduced a standard chart such as pie, line, bar, and spider charts, using physical materials, as shown in Figure 1; and the other half created bespoke layouts and mappings, as shown in Figure 2.

It is not a surprise to find out that many students created 3d physicalizations. Figure 3 (A, B, C) shows three such examples. Around 20\% of students used orientation to encode a data dimension as shown in Figure $3(\mathrm{D}, \mathrm{E})$, while orientation is anecdotally seldom used in digital visualization design projects. Some students used other unique properties of the physical world, such as shadows, perspective, lighting, liquid viscosity as shown in Figure 1(E) and pressure through gravity as shown in Figure 4. Students ended up asking themselves questions they rarely ask themselves with digital designs. P123 said "It was fun exploring new variables and marks" and P24 said "It made me think about how every mark [...] could have an underlying meaning."

As students had to choose everyday objects to represent data, they often used material that related to the data, making extensive use of symbolism, as illustrated in Figure 5. Many used food to represent food-related data such as calorie, carbs, and fluid intakes (C). As P27 said, "it helps us choose objects we have a prior relationship with, like food for food, it can make decoding the visualization quicker and easier." Beyond food, in Figure 5, P103 represented their rock climbing activities using rock-climbing related materials such as rocks, ropes and chalk (A); P108 used compact discs to represent music-related data (B); and P53 used pencils to represent study time and plastic forks to represent meals (D).

A handful of students also learned that an 


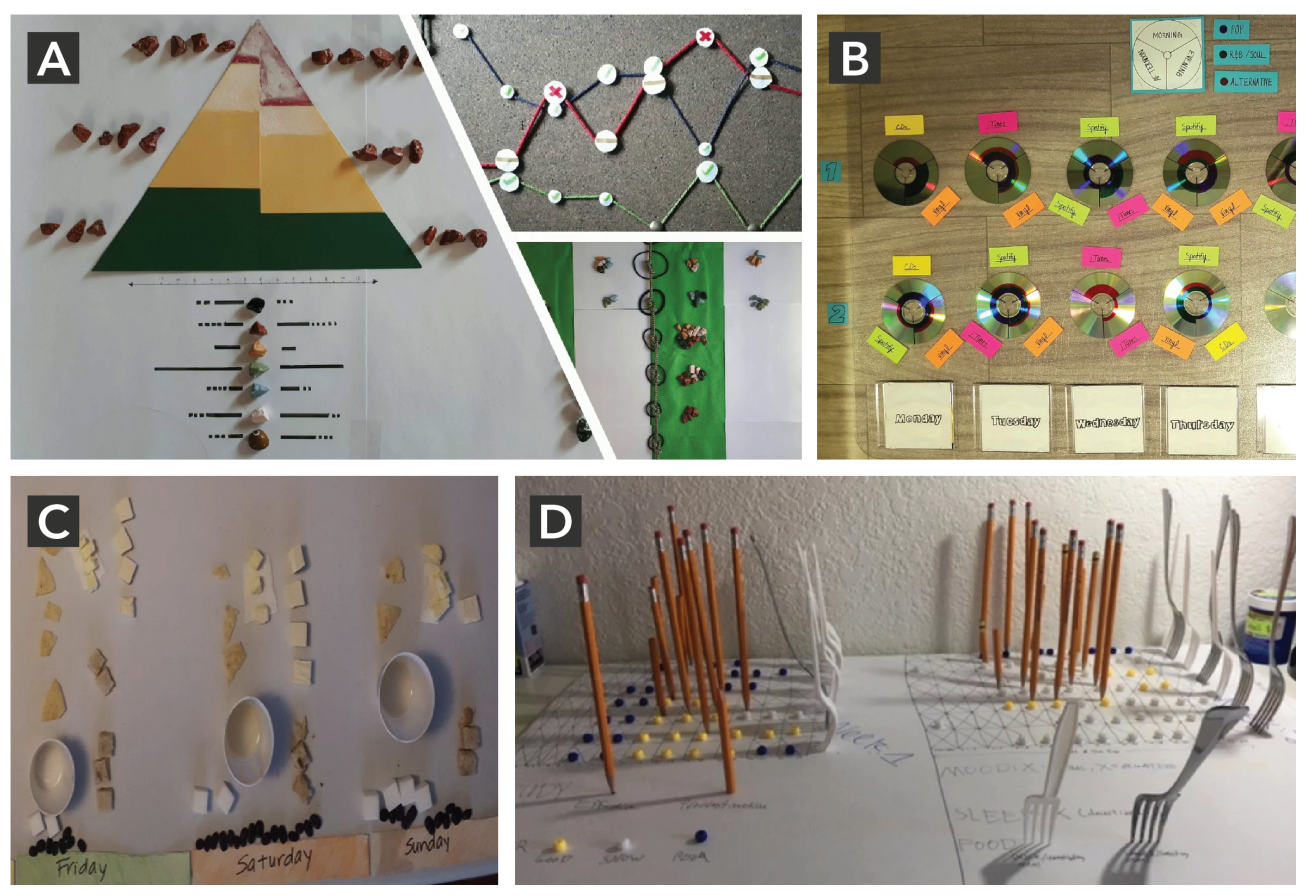

Figure 5. Examples of physicalizations that use symbolism. (A) Rock climbing activities are shown using rocks, ropes and chalk (P103, Stephanie Goodale). (B) Music listening history is encoded using compact disks (P108, Tristan Douville). (C) Diet-related data is shown using food (P35). (D) Type of activity is represented with pencils for study time and plastic forks for meals (P53, Jacob Lower).

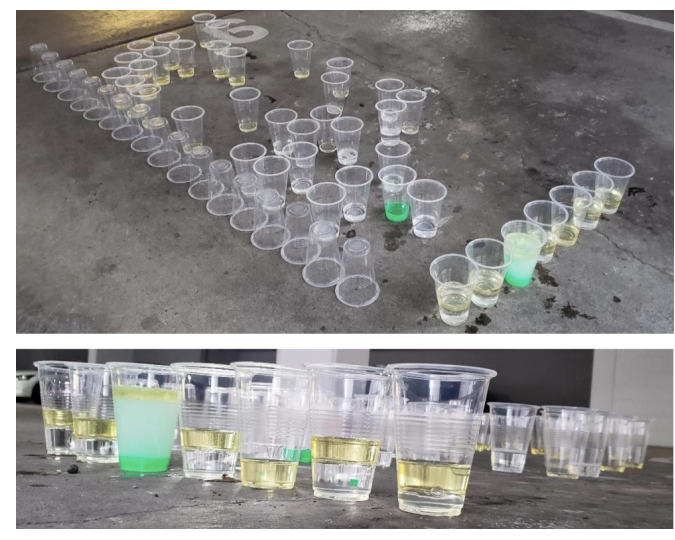

Figure 6. A relatively large-scale visualization of fluid intake that uses plastic cups (P55, James Ryan).

initial layout might not work forever, as new data is being collected. P30 learned about the "Limit in terms of number of data points that can be shown”. P55 created a large-scale physicalization using plastic cups and fluids to represent their fluid intake, as shown in Figure 6. They realized over time that the scale they had chosen was not sustainable as they were collecting more data and this was taking too much space in their home.

\section{INTERACTIONS}

Several students commented that constructing the visualization made them more aware of their data, echoing the theory behind constructive visualization [11]. For example, P35 said: "The act of physically laying out my diet on a table made me more aware of what I was putting into my body."

Around $10 \%$ of students further came up with physical interactions, some of which are shown in Figure 7. For example, P79 said: "It is fun to move the blocks around to compare days and reflect on what patterns may appear."

\section{SHARING AND STORYTELLING}

Several students mentioned sharing their physicalizations with friends and family. For example, P62 said "It's really fun to talk to people about how needy my cat is!" and P64 "The physical visualization makes the message so much stronger." P18 looked at how their sleeping patterns affect their personal behavior, by asking their children about their mood four times a day, 

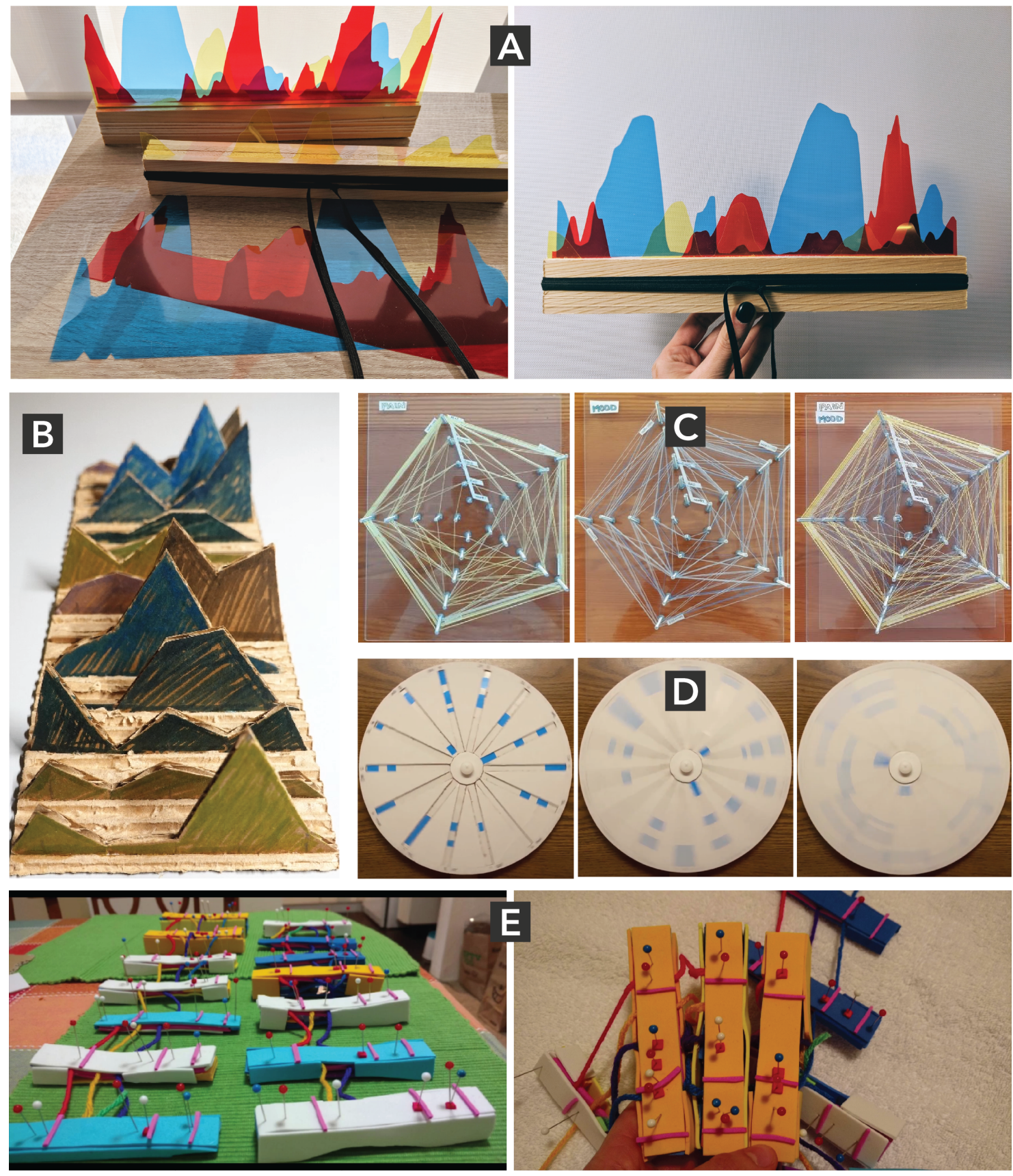

Figure 7. Examples of physical interactions. (A) Transparent layers represent different dimensions (sleep, play time and pet time of the student's cat) for different days. Overlaying layers makes comparison easy through transparency (P62, Kaitlin Erb). (B) Similar to (A), each silhouette chart represents daily phone pickups and charts can be rearranged on the depth axis (P120, Tong Zhang). (C) One stringed star plot is created for each data dimension. Here, the glyph for sleep (left) and mood (middle) are overlaid (right), making it possible to compare both dimensions (P49, Hilary Dechert Ayres). (D) Daily activities and stress are displayed on circular layouts with a rotation axis in the center. Spinning the wheel blurs the visualization and can make patterns appear - although the student found that it did not work that well (P121, yichun Zhao). (E) Each foam block represents one day with multiple attributes related to food consumption and mood, attached by colored strings. Given that the strings are a flexible material, days can be rearranged and brought together in different arrangements for comparison. While the original layout is a standard calendar grid (left), it is possible to bring together arbitrary foam blocks for close comparison, without losing the overall grid structure (P79, Meagan Pal). 

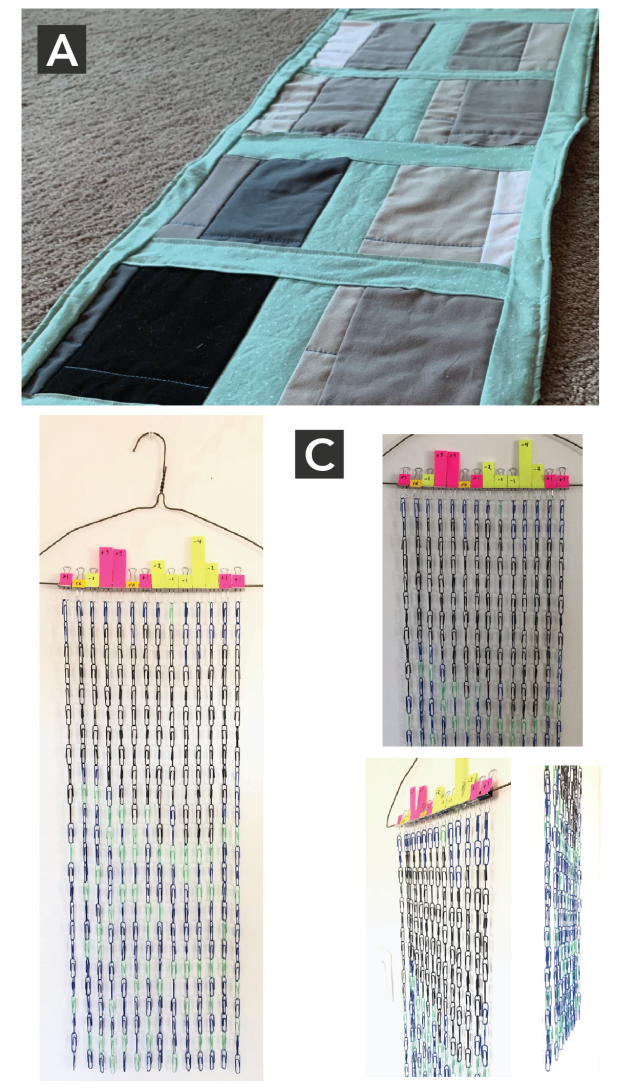
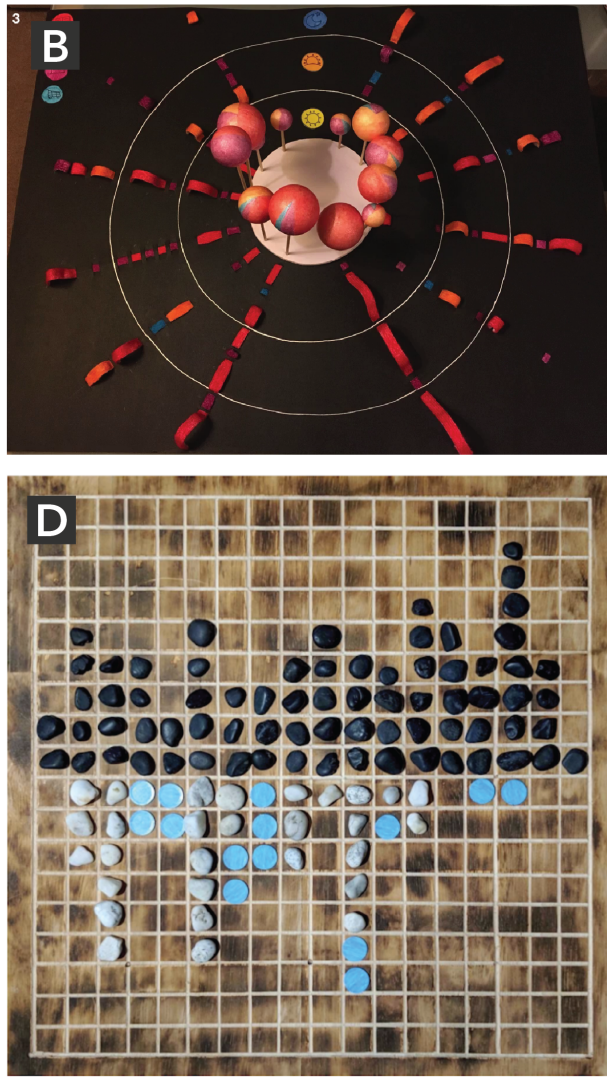

Figure 8. Examples of "data art" showing (A) screen time and stress on sewed fabric (P110, Amy vanWell); (B) weekly browser history (P64, Kathleen Chuang); (C) diet, sleep quality, physical health and mental health (P15, Brendon Earl); and (D) public transportation and phone usage (P119, Zeverin Isert).

and then used the physicalization as a medium for discussion between them and their children.

Over half of the students mentioned aesthetics and creativity when reflecting on this assignment. Figure 1(E), Figure 2(A), Figure 3(A) and (C) Figure $7(\mathrm{~A}, \mathrm{~B})$, and Figure 8 are examples assignments from such students.

\section{PERSONAL INSIGHTS}

Most students discussed having learned something about themselves. They can learn simple things. For example, P3 said "I spend way too much time on my phone", P4 "I'm happy in the mornings, sad in the evenings.", P22 "I have a tendency to overeat when I'm not socializing", P28 "I learned that I am more likely to snack when I'm tired.", and P46 "I am a much slower reader than I thought.". Yet, even these simple findings can lead to new goals. For example, P103 said "By creating this visualizations and answering my data questions, I realized I was easily climbing most of the routes I attempted, and was ready to attempt harder climbs. This was great for boosting my confidence and helping me improve my skill level."

Students sometimes learned more surprising things. For example, P35 said "I was really surprised to see that reducing the amount of caffeine was leading me to have poor sleep." P16 said "I've become more cognizant of the fact that I sit too much for long periods of time." P51 said "I learned that I actually don't listen to much music unless I'm driving, biking or walking, which is odd because I'm so passionate about it I thought I was listening to it way more."

With the first, longer version of the assignment, students got to visualize their data three times. This gave them the opportunity to act on their findings, and a few students mentioned behavioural changes. For example, P53 said "It was interesting to see how my mental health improved during my second week. I have continued to track 
my sleeping and eating, and I have improved in both fronts since the start of this project, and improved my overall health." $\mathrm{P} 14$, recovering after a knee injury, said "I found out that going out for the quick walks was really contributing to knee pain. Actually having visualized it and being able to notice that, once I had cut that out, afterwards, it actually got progressively better, I really learned a lot about myself, the activities that I do, and how they influence my body."

\section{A DIFFERENT PERSPECTIVE}

This assignment challenges assumptions. Some students realize that working under limited resources raises challenges, e.g., "It was challenging to create physical representations, considering space and cost of materials" (P103), P80 said "I realized down the road I did not have enough material to make my design possible." and P123 said "A big downside is the manual conversion of mappings that is both time and mentally consuming." On the other hand, some students also saw these constraints as design opportunities. P79 said "I think I was more conscious of the design process because I was using a limited amount of physical material"; P1 "Creating a representation with limited resources forces you to think more"; and P27 "I realized that limitations can be inspiring." P105 linked these limitations to minimalism, saying "I was forced to using limited resources in creating my visualization - this gave it a pleasing, minimalist style and showed how a lot of information can be encoded in a simple visualization", and P46 to appeal, saying it "Helped [them] better understand the aspects of an appealing visualization."

A handful of students commented on the connection they made to the data, for example P105 said "A physical representation of the data gives it weight and significance. My personal connection to the data becomes stronger when there is a physical object to tie my results to. There is a significance when I collect new data because it shapes the data's physical counterpart." A few students also commented on how easy it is to explore the data. For example, P103 said "It's easy to interact and change perspective."

\section{FINDING CREATIVITY}

The major observation I made through analyzing the results of this assignment is the extent to which students became creative or revived their creativity. At the beginning of the course a majority of them are afraid of even sketching, assuming they are not a "creative person" and struggling to think beyond standard charts. Although some students still end up creating relatively standard charts, many of them commented on how the assignment sparked their creativity.

Some students elaborated on this aspect. Some contrasted this to coding approaches, for example P31 said "Physical visualization allows for greater freedom than software." Some explained "The physical environment forced me to be more creative" (P10). Some found that it made rely less on existing visualizations, for example P29 said "It was really cool to use physical visualizations because you weren't bound by a computer display, where you also typically draw inspiration from other people's work." Others liked that it forced them to think about the context in which the visualization would be displayed. For example, P20 said "A very special and fun experience. I can easily jump off the templates or stereotypes. This sets free my imagination. It allows to combine a visualization with its context."

Several students reflected on the benefits of using physical materials. For example, P10 said "Seeing immediate changes is great, compared to having to program before seeing a result, so it is much more agile. For example, creating custom shapes is so easy in the physical world but can take forever if using a coding environment." P7 said "it helped better understand how software and computers work behind the scenes when creating visualizations." P119 said "The stones I used for visualization made reconfiguration and exploration of different designs very easy, and I think I learned the value of clustering objects to tell a story, since this is not something I would have likely tried using a coded visualization." And P44 said that "Physicality forces you to think about optimal layout."

Data from this assignment indicates that technical students are capable of being creative with data visualization design, but also that they enjoy and value being creative. For example, P94 said 
"It was fun to push myself into creating a physical visualization because this is not something I get to do often in a SE degree.", and P51 "I had a lot of fun in this project". P76 said "It really pushed me beyond what I'm used to doing.", and P47 summarized their experience as follows: "I was very surprised of how fixated I was before this realization [that I can use any objects I see in my everyday life]. I am not at all into arts and crafts. But crafting gives more of a realistic feel of what I was doing. [...] this hands-on experience has given me so many ideas on future implementations that I'm currently creating one as a personal project."

\section{LEARNING OUTCOMES AND LIMITATIONS}

In the course, this assignment happens right after students have learned about visual variables and visual marks, and have had the opportunity to practice visualization ideation through in-class group activities in a flipped classroom. They have been provided with a link to the list of physical visualizations [18] and have been shown examples of past assignments for inspiration. They have also been provided with a list of references from the visualization research literature on data physicalization through one of the graduate-student led in-class debates.

Achieving ILO2, ILO3 and ILO4 directly helps students in their main course assignment (a semester-long project in which they build a digital visualization of a dataset of their choice). It also complements the other assignments in that it allows students to achieve ILO1, and it contributes to ILO5 - After having created a visualization, you will reflect on your learning and your work. One aspect of learning that was not planned for is that several students mentioned in their reports learning about less analytical aspects of visualization, including sharing and storytelling.

The data analysis, however, revealed some less successful aspects of the assignment. One limitation stems from the requirement to collect personal data. Student questions challenged my assumption that data collection would not be a problem for technical students, however, much guidance is required for them to manage to properly collect data (in terms of data formats, how much data to collect, what tools to use). This is easily addressed through in-class discussions and by showing examples of past projects however. This would also address the challenge of assignment preparation: several students get stuck because of cost incurred, scalability and space issues, and cumbersomeness of data collection. It might be useful to request that students create an assignment specification document prior to starting data collection, for the teaching team to identify the likelihood of these issues early on.

Better preparation for this assignment could also help eliminate standard charts and mappings. One such way is to design an in-class activity at the time the assignment is released in which students would in groups, assess past personal data physicalization assignments and identify creative use of visual variables and visual marks.

\section{CONCLUSIONS}

I have presented the results of a personal data physicalization assignment implemented in an information visualization course for CS and SE students, as an attempt to spark creativity among students who too often underestimate their creative capabilities.

By combining the benefits of personal data visualization and physical visualization, students who are able technically and have some visualization knowledge did learn through building physicalizations. This complements findings that creating physicalizations has learning benefits for non-technical audiences with little expertise in visualization [15], [10]. Personal Data Physicalization asks students to think about data collection, to explore new mappings and to think about layout constraints, cost and quantity of visual marks. It allows them to propose creative interaction techniques and to create objects they might share with their relatives.

It is also an assignment that allows students to learn things about themselves, to reflect, and to change. It allows them to connect with their data in unique ways. As P110 put it after they knitted fabric to represent their screen time and stress levels (see Figure 8(A)), "Having a tangible object that reflects a point in time in my life is very satisfying."

Through this assignment students also demonstrated how stressed they are, how much they think about their mental and physical health. 
Could personal data physicalization be therapeutic, allowing people to externalize these mental health issues that so many students face?

\section{ACKNOWLEDGMENTS}

I thank the students at the University of Victoria I interacted with in these courses, for allowing me to use their work and for making this such a fun assignment to grade.

\section{- REFERENCES}

1. D. Huang et al., "Personal Visualization and Personal Visual Analytics," IEEE TVCG, 2015.

2. Z. Pousman, J. Stasko, and M. Mateas, "Casual Information Visualization: Depictions of Data in Everyday Life," IEEE TVCG, 2007.

3. A. Thudt, C. Perin, W. Willett, and S. Carpendale, "Subjectivity in personal storytelling with visualization," Information Design Journal, 2017.

4. F. Botros, C. Perin, B. A. Aseniero, and S. Carpendale, "Go and Grow: Mapping Personal Data to a Living Plant," in Proc. AVI, 2016.

5. A. Thudt, D. Baur, S. Huron, and S. Carpendale, "Visual mementos: Reflecting memories with personal data," IEEE TVCG, 2016.

6. C. Perin, "Cycles and (A)Symmetry | Exploring the Design of Shareable Personal Visualizations," in IEEE VIS Arts Program, 2018.

7. B. A. Aseniero, C. Perin et al., "Activity river: Visualizing planned and logged personal activities for reflection," in Proc. AVI, 2020.

8. A. Thudt, U. Hinrichs, S. Huron, and S. Carpendale, "Self-Reflection and Personal Physicalization Construction," in Proc. CHI, 2018.

9. Y. Jansen, P. Dragicevic, P. Isenberg, J. Alexander, A. Karnik, J. Kildal, S. Subramanian, and K. Hornbæk, "Opportunities and challenges for data physicalization," in Proc. CHI, 2015.

10. S. Huron, Y. Jansen, and S. Carpendale, "Constructing visual representations: Investigating the use of tangible tokens," IEEE TVCG, 2014.

11. S. Huron, S. Carpendale, A. Thudt, A. Tang, and M. Mauerer, "Constructive visualization," in Proc. DIS, 2014.

12. S. Huron, S. Carpendale, J. Boy, and J.-D. Fekete, "Using viskit: A manual for running a constructive visualization workshop," in Pedagogy of Data Visualization Workshop at IEEE VIS 2016, 2016.
13. S. Huron, P. Gourlet, U. Hinrichs, T. Hogan, and Y. Jansen, "Let's get physical: Promoting data physicalization in workshop formats," in Proc. DIS, 2017.

14. W. Willett and S. Huron, "A constructive classroom exercise for teaching infovis," in Pedagogy of Data Visualization Workshop at IEEE VIS 2016, 2016.

15. R. Bhargava and C. D'Ignazio, "Data sculptures as a playful and low-tech introduction to working with data," in Pedagogy \& Physicalization Workshop at DIS, 2017.

16. J. Hurtienne and D. Reinhardt, "Teaching data physicalisation to hci students-," in Pedagogy \& Physicalization Workshop at DIS, 2017.

17. A. V. Moere and S. Patel, "The physical visualization of information: designing data sculptures in an educational context," in Visual information communication, 2009.

18. P. Dragicevic and Y. Jansen, "List of physical visualizations," www.dataphys.org/list, 2012, last accessed 2021-07-27.

Charles Perin is an Assistant Professor in the Department of Computer Science at the University of Victoria. He received his Ph.D. from University Paris-Sud. His research focuses on designing and studying new interactions for visualizations and on understanding how people may make use of and interact with visualizations in their everyday lives, including mobile and physical visualization. He has published over 30 peer-reviewed journal articles and conference papers at top-tier venues in the fields of visualization and human-computer interaction and has served the international community in multiple roles, such as PC member for IEEE Infovis/VIS and Graphics Interfaces, and Associate Chair/Editor for ACM CHI and ACM ISS. He has been in the organizing committee of the IEEE VIS conference for the past five years and is the Co-General Chair for the Vis Arts Program at IEEE VIS in 2021. Contact him at cperin@uvic.ca. 